\title{
Manajemen Pemupukan Organik dan Anorganik Kelapa Sawit di Sekunyir Estate, Kalimantan Tengah
}

Organic and Inorganic Fertilizing Management of Palm Oil in Sekunyir Estate, Central Borneo

\author{
Gery Juliansyah dan Supijatno*
}

Departemen Agronomi dan Hortikultura, Fakultas Pertanian, Institut Pertanian Bogor (Bogor Agricultural University), J1. Meranti, Kampus IPB Darmaga, Bogor 16680, Indonesia Telp. \& Faks.62-251-8629353 e-mail agronipb@indo.net.id

*Penulis Korespondensi : supijatno@yahoo.co.id

Disetujui : 15 Januari 2018 / Published Online 23 Januari 2018

\begin{abstract}
The research was conducted at Sekunyir Estate, Central Borneo from February 9 to June 82016. Palm oil trees fertilization is aimed to fulfill plant's nutrition needs, thus it can produce optimally. Fulfilling palm trees need of nutrition supplied by organic materials through waste of empty fruit bunches and by inorganic materials. Fertilizing contribute take $60 \%$ of total oil palm production cost and good management is needed for its maintenance. Observations showed that fertilization in Sekunyir Estate management has been very good at apply the concept of effectiveness and efficiency. Effectiveness in fertilizing management is done through applying $4 R$ (right time, right quantity, right type, and right method). Efficiency is aimed so the production input is fit to the need. Sekunyir Estate has cost efficiency by $60 \%$ in inorganic fertilizer and $55 \%$ on an organic fertilizer. EFB application in Sekunyir Estate mot significantly effect productivity and reduction of pottasioum fertilizer because influenced by technical application in the field. Organic and inorganic fertilizing management had to be managed well in order to promote optimal and continuous production of palm oil.
\end{abstract}

Keywords : effective, efficien, inorganic fertilizer, management, organic fertilizer

\begin{abstract}
ABSTRAK
Kegiatan penelitian dilaksanakan di Sekunyir Estate, Kalimantan Tengah dari tanggal 9 Februari hingga 8 Juni 2016. Pemupukan kelapa sawit bertujuan untuk memenuhi kebutuhan hara tanaman sehingga dapat berproduksi optimal. Pemenuhan kebutuhan hara tanaman kelapa sawit dilakukan secara organik dengan memanfaatkan limbah TKKS (Tandan Kosong Kelapa Sawit) dan anorganik. Biaya pemupukan sebesar $60 \%$ dari total seluruh biaya produksi kelapa sawit sehingga perlu manajemen yang baik dalam pengelolaannya. Hasil pengamatan menunjukan bahwa manajemen pemupukan di Sekunyir Estate sudah sangat baik dengan menerapkan konsep efektivitas dan efisiensi. Efektifitas dilihat dari aplikasi pemupukan dengan konsep 4T yaitu tepat (waktu, dosis, jenis dan cara). Efisiensi bertujuan agar penggunaan input produksi dapat sesuai dengan kebutuhan. Sekunyir Estate telah melakukan efisiensi biaya sebesar $60 \%$ pada pemupukan anorganik dan 55\% pada pemupukan organik. Aplikasi TKKS di Sekunyir Estate tidak berpengaruh nyata terhadap produktivitas dan pengurangan pupuk kalium karena dipengaruhi oleh aplikasi teknis di lapangan. Manajemen pemupukan organik dan anorganik pada kelapa sawit harus dikelola secara baik dan benar agar menghasilkan produksi kelapa sawit yang optimal serta berkelanjutan.
\end{abstract}

Kata kunci : efektif, efisien, pupuk anorganik, pupuk organik, manajemen 


\section{PENDAHULUAN}

Kelapa sawit (Elaeis guineensis Jacq.) merupakan tanaman tropis yang menghasilkan minyak nabati terbesar dunia. Kebutuhan dunia akan minyak nabati terus meningkat seiring dengan pertambahan jumlah penduduk. Menurut Cheng (2010) konsumsi minyak nabati dunia pada tahun 2009 mencapai 132.8 juta ton dari konsumsi tersebut sekitar $34 \%$ dipenuhi dari minyak kelapa sawit. Kebutuhan minyak nabati akan terus meningkat hingga tahun 2020 mencapai 236 juta ton (Oil World, 2010). Pertumbuhan industri minyak kelapa sawit yang tinggi disebabkan oleh keunggulan biaya produksi dalam budidaya kelapa sawit. Kelapa sawit adalah tanaman penghasil minyak nabati yang sangat produktif jika dibandingkan dengan tanaman penghasil minyak nabati lainnya. Indonesia merupakan negara penghasil minyak kelapa sawit terbesar di dunia. Luas areal kelapa sawit Indonesia pada tahun 2013 mencapai 10465020 ha dengan produksi CPO sebesar 5556401 ton dan produktivitas $3536 \mathrm{~kg}$ ha per tahun. Nilai ekspor kelapa sawit Indonesia mencapai 20577976 ton CPO (Crude Palm Oil) dengan nilai sebesar \$15 838850.00 sehingga menjadi sumber devisa terbesar dan menjadikan Indonesia sebagai negara produsen kelapa sawit terbesar dunia (Ditjenbun, 2013).

Kebutuhan yang tinggi terhadap minyak kelapa sawit pada masa yang akan datang harus didukung dengan produktivitas tinggi. Pemupukan adalah salah satu upaya intensifikasi dalam meningkatkan produktivitas kelapa sawit. Tujuan pemupukan yaitu menyediakan hara yang cukup bagi tanaman agar mampu berproduksi optimal. Penyediaan hara tanaman dapat dilakukan baik secara organik maupun anorganik. Pupuk organik merupakan hasil akhir dari penguraian bagianbagian atau sisa-sisa (serasah) tanaman dan hewan. TKKS (Tandan Kosong Kelapa Sawit) merupakan sisa tanaman yang bermanfaat sebagai pupuk. Aplikasi TKKS sebanyak 40 ton $\mathrm{ha}^{-1}$ dikombinasikan dengan $60 \%$ dosis pupuk urea dan rock phosphat dari standar mampu meningkatkan produksi TBS hingga 34\% dibandingkan perlakuan standar (Rahutomo et al., 2008). Biaya pemupukan pada kelapa sawit berkisar antara 40-60\% dari biaya pemeliharan tanaman atau sekitar 30\% dari total biaya produksi (Goh dan Hardter, 2003).

$$
\text { Efisiensi pemupukan perlu }
$$

mempertimbangkan hubungan antara unsur hara yang terserap dengan sumberdaya yang dibutuhkan. Biaya dan tenaga kerja merupakan sumberdaya yang penting dalam aspek pemupukan. Kebutuhan biaya dalam pemupukan meliputi biaya pengadaan pupuk, biaya transportasi dan biaya tenaga kerja. Penggunaan pupuk yang sesuai kebutuhan tanaman akan mengurangi jumlah biaya yang diperlukan sehingga lebih efisien. Jumlah sarana transportasi ditentukan oleh luas lahan yang akan dilakukan pemupukan. Biaya tenaga kerja ditentukan berdasarkan prestasi kerja yang dihasilkan. Jumlah tenaga pemupuk dan prestasi kerja pemupuk akan mempengaruhi target waktu penyelesaian pemupukan. Maka perlu dilakukan manajemen yang baik dalam pengelolaan pemupukan. Manajemen pemupukan organik dan anorganik yang baik akan mendapatkan hasil produksi yang optimum, ramah lingkungan serta berkelanjutan.

Penelitian ini bertujuan untuk meningkatkan pengetahuan dan kemampuan mahasiswa tentang budidaya tanaman kelapa sawit yang baik secara teknis maupun manajerial secara nyata di lapangan serta melatih mahasiswa menganalisis dari setiap kegiatan di lapangan. Tujuan khusus yaitu mempelajari manajemen pemupukan organik dan anorganik pada tanaman kelapa sawit.

\section{METODE PENELITIAN}

Kegiatan penelitian dilaksanakan di Sekunyir Estate, Minamas Plantation, Kalimantan Tengah. Penelitian dilaksanakan selama empat bulan mulai dari 9 Februari hingga 8 Juni 2016. Kegiatan penelitian meliputi pelaksanaan teknis di lapangan bersama asisten afdeling sebagai pembimbing dan wawancara tenaga kerja serta diskusi terbuka bersama mandor. Selama kegiatan penelitian juga melakukan pengumpulan laporan harian, laporan bulanan, laporan tahunan dan arsip kebun. Kegiatan penelitian ini, dikerjakan langsung di lapangan sebagai karyawan harian lepas (KHL) selama satu bulan, satu bulan kemudian sebagai pendamping mandor dan dua bulan setelahnya sebagai pendamping asisten afdeling. Kegiatan khusus yang dilaksanakan selama penelitian difokuskan kepada manajemen pemupukan organik dan anorganik. Manajemen pemupukan ditujukan untuk mengetahui efektifitas dan efisiensi pemupukan yang dilakukan kebun serta manfaat yang didapat pada aplikasi pupuk organik. Pengamatan ini dilaksanakan saat sebagai KHL, pendamping mandor dan pendamping asisten afdeling.

Pengumpulan data dan informasi yang dilakukan meliputi pengambilan data primer dan data sekunder. Data primer diperoleh melalui pengamatan langsung di lapangan selama kegiatan 
menjadi KHL, pendamping mandor, dan pendamping asisten afdeling. Data sekunder diperoleh dari data umum dan data khusus pemupukan perusahaan. Data umum terdiri dari data curah hujan, peta jenis tanah, struktur organisasi dan ketenagakerjaan. Data khusus pemupukan diperoleh dari : (1) Dosis pupuk anorganik pada pemupukan $100 \%$ anorganik dengan pemupukan anorganik + organik pada tahun 2010-2015. (2) Produktivitas TBS pada lahan yang diaplikasi pupuk $100 \%$ anorganik dengan aplikasi pupuk anorganik + organik pada tahun 2007-2015. (3) Pencapaian realisasi pemupukan organik dan anorganik dari program yang direncanakan pada tahun 2011-2015.

Pengamatan yang dilakukan selama penelitian untuk melengkapi data primer terdiri dari : (a) Ketepatan waktu pemupukan. Mengamati waktu realisasi pemupukan di lapang kemudian dianalisis berdasarkan data curah hujan pada saat aplikasi pemupukan. (b) Ketepatan dosis pupuk. Mengamati dosis pupuk pada jumlah tanaman yang dipupuk oleh pekerja hingga pasar tengah. Teknis pemupukan dengan menggunakan mangkuk sebagai alat kalibrasi pada pemupukan anorganik (CCM 44). Pada pemupukan organik dengan menghitung jumlah TKKS yang diaplikasikan di lapang. Pengamatan dilakukan terhadap 5 orang pemupuk dengan tiga kali ulangan. (c) Kesesuaian jenis pupuk. Melakukan pengamatan realisasi jenis pupuk yang digunakan di lapang kemudian membandingkan dengan rekomendasi yang diberikan oleh departemen riset kebun. (d) Ketepatan cara pemupukan. Mengukur tinggi aplikasi pupuk TKKS dan jarak pada aplikasi pupuk anorganik (CCM 44) yang terdekat dari batang tanaman kelapa sawit kemudian dibandingkan dengan standar kebun. Pengamatan dilakukan terhadap 5 orang pemupuk (setiap tenaga pemupuk diambil sampel sebanyak 17 tanaman) dengan tiga kali ulangan. (e) Efisiensi biaya. Melakukan analisis terhadap biaya pemupukan organik dan anorganik. (f) Efisiensi tenaga kerja. Menghitung jumlah tenaga kerja dan prestasi kerja pemupuk kemudian dibandingkan dengan standar kerja yang telah ditetapkan oleh kebun. Data yang diperoleh dianalisis secara kuantitatif dan kualitatif dengan metode analisis deskriptif, mencari rata-rata, persentase hasil pengamatan, dan menggunakan uji t-student kemudian diuraikan secara deskriptif dengan membandingkan terhadap norma baku yang berlaku pada perkebunan kelapa sawit secara umum dan standar yang telah ditetapkan oleh perusahaan kemudian dilakukan juga studi pustaka untuk membandingkannya.

\section{HASIL DAN PEMBAHASAN}

\section{Kondisi Umum}

Sekunyir Estate (SKE) merupakan perkebunan kelapa sawit yang secara administratif berlokasi di Desa Amin Jaya, Kecamatan Pangkalan Banteng, Kabupaten Kotawaringin Barat, Provinsi Kalimantan Tengah. Secara geografis Sekunyir Estate terletak pada $2^{0} 23$ ' 29" $-2^{\circ} 23^{\prime} 36^{\prime \prime} \mathrm{LS}$ dan $111^{0} 59^{\prime} 10^{\prime \prime}-112^{0} 04^{\prime} 55^{\prime}$ BT.

Iklim di Sekunyir Estate memiliki iklim sangat basah berdasarkan tipe iklim SchmidtFerguson, dimana curah hujannya sangat tinggi untuk setiap tahunnya. Curah hujan merata sepanjang tahun, sehingga persediaan air untuk tanaman kelapa sawit mencukupi. Curah hujan yang terjadi dari tahun 2006-2015 berkisar 3015 $\mathrm{mm}$ dengan rata-rata $464 \mathrm{~mm}$ per tahun. Sedangkan rata-rata jumlah hari hujan yaitu $13 \mathrm{hh}$ per tahun. Topografi areal Sekunyir Estate berada pada ketinggian kurang dari $200 \mathrm{~m}$ dpl (diatas permukaan laut) dengan kemiringan $0-15^{\circ}$ yang merupakan daerah tergenang sampai bergelombang. Kelas lahan Sekunyir Estate sekitar 2629.46 ha (78\%) merupakan kelas S2 (sesuai) dan sisanya 742.28 (22\%) merupakan kelas S3 (kurang sesuai).

Luas dari Sekunyir Estate adalah 3.555,20 ha dengan luas areal tanam sebesar 326.17 ha. Adapun tata guna lahan digunakan sebagai berikut : (1) Pembibitan seluas 17 ha. (2) Areal tanam seluas 3326.17 ha. (3) Areal prasarana dan bangunan seluas 194.86 ha. (4) Area konservasi seluas 17.16 ha.

Kelapa sawit di Sekunyir Estate ditanam pertama kali pada tahun 1992 sampai tahun 1995 kemudian tahun 2005 dan 2007 dilakukan penanaman kelapa sawit sisipan. Tahun 2013 hingga 2015 dilakukan peremajaan tanaman (replanting). Luas lahan penanaman tahun 1992 sampai tahun 1995 sebesar 2665.87 ha dan luas lahan tahun 2013 sampai 2015 sebesar 660.30 ha. Jenis benih yang ditanam berasal dari Pusat Penelitian Marihat dan PT. Socfin Indonesia. Varietas yang ditanam adalah jenis Tenera yaitu hasil persilangan dari Dura dan Pisifera. Ketebalan cangkang Tenera adalah 1-2,5 mm, dengan ketebalan pericarp 3-10 mm. Status tanaman di Sekunyir Estate terdiri dari TBM (Tanaman Belum Menghasilkan) dan TM (Tanaman Menghasilkan).

Produktivitas rata-rata tandan buah segar (TBS) di Sekunyir Estate selama sembilan tahun terakhir adalah 19.97 ton ha $^{-1}$ tahun $^{-1}$. Rata-rata produksi TBS Sekunyir Estate dapat dilihat pada Tabel 1. Produktivitas rata-rata TBS Sekunyir Estate pada tahun 2007-2015 sebesar 62874.93 ton tahun ${ }^{-1}$ dengan produktivitas rata-rata 19.97 ton ha $^{-1}$ tahun $^{-1}$. Berdasarkan data BPS (2014) 
rata-rata produktivitas $\mathrm{CPO}$ nasional sebesar 3.57 ton $\mathrm{ha}^{-1}$ tahun $^{-1}$. Produktivitas kelapa sawit
Sekunyir Estate sudah melebihi rata-rata produktivitas nasional.

Tabel 1. Produksi dan produktivitas di Sikunyir Estate tahun 2007-2015

\begin{tabular}{|c|c|c|}
\hline Tahun & $\begin{array}{l}\text { Produksi TBS } \\
\text { (ton tahun }^{-1)}\end{array}$ & 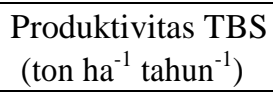 \\
\hline 2007 & 93278.37 & 27.79 \\
\hline 2008 & 43741.88 & 13.03 \\
\hline 2009 & 94887.91 & 28.17 \\
\hline 2010 & 56776.40 & 16.85 \\
\hline 2011 & 42940.70 & 12.75 \\
\hline 2012 & 56366.02 & 18.30 \\
\hline 2013 & 79928.68 & 28.22 \\
\hline 2014 & 35079.46 & 14.62 \\
\hline 2015 & 5953273 & 24.81 \\
\hline Rata-rata & 62874.93 & 19.97 \\
\hline
\end{tabular}

\section{Efektifitas Pemupukan}

Tepat Waktu Pemupukan. Waktu pemupukan merupakan syarat efektifnya aplikasi pupuk pada tanaman. Menurut Pahan (2010) waktu dan frekuensi pemupukan ditentukan oleh iklim (terutama curah hujan), sifat fisik tanah, logistik serta adanya sifat sinergis dan antagonis antar unsur hara. Curah hujan berperan sebagai parameter dalam menentukan waktu aplikasi pemupukan. Waktu aplikasi pemupukan di Sekunyir Estate dapat dilihat pada Tabel 2.

Tabel 2. Realisasi waktu pemupukan pada semester 2 berdasarkan jenis pupuk tahun 2016

\begin{tabular}{|c|c|c|c|c|c|}
\hline \multirow{2}{*}{$\begin{array}{l}\text { Bulan } \\
\text { aplikasi }\end{array}$} & \multicolumn{3}{|c|}{ Jenis pupuk } & \multirow{2}{*}{$\begin{array}{l}\text { Hari } \\
\text { hujan }\end{array}$} & \multirow{2}{*}{$\begin{array}{l}\text { Curah hujan } \\
\text { bulan }^{-1} \text { (mm) }\end{array}$} \\
\hline & CCM $44(\mathrm{~kg})$ & Kieserit (kg) & HGFB (kg) & & \\
\hline Februari & 124222 & & 9704 & 18 & 443 \\
\hline Maret & 206373 & 5974 & 2266 & 16 & 480 \\
\hline April & 210078 & 5202 & & 13 & 333 \\
\hline Mei & 147943 & 2782 & & 14 & 208 \\
\hline
\end{tabular}

PPKS (2005) menyatakan bahwa aplikasi pemupukan optimum dilakukan pada saat curah hujan 100-250 mm bulan ${ }^{-1}$ sedangkan curah hujan minimum adalah $60 \mathrm{~mm}^{\text {bulan }}{ }^{-1}$ dan maksimum $300 \mathrm{~mm}$ bulan $^{-1}$. Waktu aplikasi pada bulan Februari dan Maret terdapat curah hujan yang tinggi yaitu diatas $400 \mathrm{~mm}$ bulan $^{-1}$ sedangkan aplikasi pada bulan April dan Mei berada pada curah hujan 200-300 mm bulan ${ }^{-1}$. Aplikasi pupuk di Sekunyir Estate pada bulan Februari dan Maret terjadi kehilangan pupuk akibat curah hujan yang tinggi. sedangkan pada bulan April dan Mei pelaksanaan aplikasi pupuk sudah tepat waktu berdasarkan curah hujan yang terjadi. Ketidaktepatan waktu aplikasi ini disebabkan oleh pengaruh iklim yang tidak dapat diprediksi.

Adiwiganda (2007) menyatakan bahwa kesulitan pelaksanaan pemupukan tepat waktu disebabkan karena terjadinya curah hujan yang sulit diprediksi yaitu kandungan air dalam tanah yang tidak sesuai dengan persyaratan dalam aplikasi pupuk. Sehingga perlu dilakukan perhitungan defisit air untuk mengetahui kandungan air tanah yang dapat dilihat pada Tabel 3.

Tabel 3. Hubungan defisit air terhadap ketepatan waktu pemupukan harian bulan Februari tahun 2016

\begin{tabular}{clccccccc}
\hline \multirow{2}{*}{ Tanggal } & $\begin{array}{l}\text { Jenis } \\
\text { pupuk }\end{array}$ & $(\mathrm{C})$ & $(\mathrm{D})$ & $(\mathrm{E})$ & $(\mathrm{F})=\mathrm{C}+\mathrm{D}-\mathrm{E}$ & $(\mathrm{G})$ & $(\mathrm{H})=\mathrm{F}-\mathrm{D}$ & $(\mathrm{I})$ \\
\hline 23 & CCM44 & 12,5 & 200 & 5 & 207,5 & 200 & 7,5 & 0 \\
24 & CCM44 & 0 & 200 & 5 & 195 & 195 & 0 & 0 \\
25 & CCM44 & 5 & 195 & 5 & 195 & 195 & 0 & 0 \\
26 & HGFB & 0 & 195 & 5 & 190 & 190 & 0 & 0 \\
27 & HGFB & 43 & 190 & 5 & 228 & 200 & 38 & 0 \\
\hline
\end{tabular}

Keterangan: C: curah hujan (mm), D: cadangan awal (mm), E: evapotranspirasi (mm), F: keseimbangan (mm), G: cadangan akhir $(\mathrm{mm}), \mathrm{H}$ : drainase $(\mathrm{mm})$, I: defisit air $(\mathrm{mm})$. 
Aplikasi pupuk HGFB pada tanggal 27 Februari terjadi drainase air sebanyak $38 \mathrm{~mm}$ (Tabel 3), hal ini memungkinkan terjadinya kehilangan pupuk karena terbawa air pada permukaan tanah. Perhitungan ini sesuai dengan hasil riset PPKS (2005) yaitu pemupukan dilakukan apabila sudah turun hujan $50 \mathrm{~mm}$ per 10 hari dan waktu dilarang melakukan pemupukan khusus untuk jenis pupuk mudah menguap dan larut aplikasi dilakukan apabila tidak ada hujan 20 hari berturut-turut, terdapat jumlah hujan 20 hari berturut turut dengan intensitas hujan harian 30 mm per hari serta tanah jenuh air (lewat kapasitas lapang).

Tepat Dosis Pemupukan. Kebutuhan jumlah hara yang tepat bagi tanaman akan mempengaruhi produktivitas tanaman. Pemupukan anorganik harus sesuai dengan dosis rekomendasi karena tanaman membutuhkan nutrisi yang cukup untuk menghasilkan bobot TBS yang dihasilkan. Ketepatan dosis aplikasi pemupukan organik dan anorganik disajikan pada Tabel 4.

Tabel 4. Ketepatan dosis aplikasi pemupukan organik dan anorganik di Sekunyir Estate

\begin{tabular}{cccccccccccccccccccc}
\hline Tepat dosis & 1 & 2 & 3 & 4 & 5 & 6 & 7 & 8 & 9 & 10 & 11 & 12 & 13 & 14 & 15 & 16 & $\begin{array}{c}\text { Rata- } \\
\text { rata }\end{array}$ \\
\hline $\begin{array}{c}\text { TKKS } \\
\begin{array}{c}(\%) \\
\text { Anorganik } \\
(\%)\end{array}\end{array}$ & 114 & 109 & 110 & 101 & 99 & 96 & 94 & 92 & 92 & 93 & 94 & 86 & 80 & 70 & 60 & 58 & 53 & 88 \\
& 99 & 98 & 97 & 93 & 97 & 93 & 93 & 90 & 95 & 91 & 92 & 93 & 93 & 95 & 95 & 90 & 88 & 94 \\
\hline
\end{tabular}

Persentase tepat dosis aplikasi pupuk anorganik pada 17 tanaman di Sekunyir Estate tinggi yaitu rata-rata sebesar $94 \%$ per tanaman dari standar $100 \%$ per tanaman yang telah ditetapkan (Tabel 4). Faktor penentu keberhasilan aplikasi pemupukan tergantung dari kualitas dari tenaga pemupuk. Tenaga pemupuk di Sekunyir Estate memiliki pengalaman yang baik karena terdiri dari karyawan pupuk tetap yang telah bekerja lama sebagai tenaga aplikasi pupuk. Ketepatan dosis aplikasi TKKS di Sekunyir Estate menunjukan bahwa rata-rata sebesar $88 \%$ per tanaman dari standar $100 \%$ per tanaman yang telah ditetapkan perusahaan (Tabel 4). Banyak faktor yang mempengaruhi tingkat keberhasilan tepat dosis pada aplikasi pupuk organik. Pertama, faktor tenaga kerja menentukan kualitas aplikasi TKKS. Karyawan aplikasi TKKS di Sekunyir Estate masih menggunakan tenaga borong karena kebijakan perusahaan dalam upaya efisiensi biaya aplikasi. Tenaga borong harus dilakukan pengawasan yang baik oleh supervisi sebab kualitas pekerjaan borong selalu rendah karena selalu mengejar target. Kedua, aplikasi pada TBM tingkat kesulitannya lebih tinggi dibandingkan pada TM. Faktor kepadatan tanah dan gulma pada TBM sering menjadi kendala saat aplikasi di lapang. Ketiga, persentase tepat dosis setiap tanaman berbeda. Data menunjukan bahwa dosis aplikasi terbanyak dilakukan pada tanaman pertama yaitu $114 \%$ yang berada didekat tumpukan TKKS di collection road sehingga untuk tanaman selanjutnya pada tanaman ke-17 maka dosis aplikasi akan berkurang.

Tepat Jenis Pemupukan. Poeloengan et al. (2003) menyatakan beberapa dasar pertimbangan yang digunakan dalam penentuan jenis pupuk antara lain adalah umur tanaman, gejala defisiensi hara, kondisi lahan dan harga pupuk. Penentuan jenis pupuk di Sekunyir Estate dilakukan oleh departemen riset Minamas yaitu MRC (Minamas Research Center). Pertimbangan MRC dalam pemilihan jenis pupuk disajikan pada Tabel 5 .

Tabel 5. Pertimbangan MRC dalam pemilihan jenis pupuk di Sekunyir Estate

\begin{tabular}{lccc}
\hline \multirow{2}{*}{ Dasar pertimbangan } & \multicolumn{3}{c}{ Jenis pupuk } \\
\cline { 2 - 4 } Efisiensi biaya & CCM 44 & HGFB & Kieserit \\
Ketersediaan pupuk & $\sqrt{ }$ & $\sqrt{ }$ & $\sqrt{ }$ \\
Ketersediaan tenaga kerja & $\sqrt{ }$ & & \\
Tepat waktu pemupukan & $\sqrt{ }$ & $\sqrt{ }$ \\
Memenuhi unsur hara tanaman & $\sqrt{ }$ & & $\sqrt{ }$ \\
Mengurangi kehilangan hara & $\sqrt{ }$ & $\sqrt{ }$ \\
Defisiensi hara & $\sqrt{ }$ & & \\
\hline
\end{tabular}


Data menunjukan bahwa jenis pupuk yang digunakan di Sekunyir Estate adalah jenis pupuk majemuk CCM $44\left(\mathrm{~N} 12 \%, \mathrm{P}_{2} \mathrm{O}_{5} 6 \%, \mathrm{~K}_{2} \mathrm{O}\right.$ $22 \%, \mathrm{MgO} 3 \%$ ), HGFB dan kieserit. Pupuk ini digunakan karena menyesuaikan dengan kondisi kebun serta pupuk majemuk memiliki efisiensi yang baik dibandingkan penggunaan pupuk tunggal. Menurut Andayani (2008) kelebihan penggunaan pupuk tunggal adalah harganya murah dan pemberian pupuk bisa sesuai dengan dosis yang diinginkan. Namun, penggunaan pupuk tunggal juga memiliki kekurangan yaitu membutuhkan tenaga dan biaya yang besar karena pada tiap aplikasi hanya mengaplikasikan satu jenis pupuk saja.

Tepat Cara Pemupukan. Cara aplikasi dalam pemupukan yaitu terdiri dari di tabur, benam dan semprot. Pemilihan cara aplikasi didasarkan antara lain jenis pupuk, efisiensi, ketersediaan alat, kondisi lahan dan unsur tanaman (PPKS, 2005). Sekunyir Estate menerapkan konsep cara aplikasi dengan ditabur. Konsep ini dinilai lebih efisien waktu dan biaya, tepat dilakukan pada kondisi lahan yang datar, dan sesuai dengan jenis aplikasi pupuk. Ketepatan cara aplikasi pemupukan organik dan anorganik disajikan pada Tabel 6.

Tabel 6. Ketepatan cara aplikasi pemupukan organik dan anorganik di Sekunyir Estate

\begin{tabular}{ccccccccccccccccccc}
\hline Tepat cara & \multicolumn{1}{c}{} & 1 & 2 & 3 & 4 & 5 & 6 & 7 & 8 & 9 & 10 & 11 & 12 & 13 & 14 & 15 & $\begin{array}{c}\text { Rata- } \\
\text { rata }\end{array}$ \\
\hline $\begin{array}{c}\text { TKKS } \\
(\%)\end{array}$ & 100 & 100 & 100 & 100 & 100 & 100 & 100 & 100 & 100 & 100 & 100 & 100 & 100 & 100 & 100 & 100 & 100 & 100 \\
$\begin{array}{c}\text { Anorganik } \\
(\%)\end{array}$ & 104 & 109 & 111 & 106 & 108 & 109 & 108 & 109 & 109 & 110 & 110 & 108 & 108 & 107 & 109 & 102 & 104 & 108 \\
\hline
\end{tabular}

Tabel menunjukan bahwa rata-rata persentase tepat cara aplikasi pupuk anorganik yaitu sebesar $108 \%$ per tanaman (Tabel 6). Aplikasi cenderung diluar batas yang seharusnya diterapkan yaitu $1 \mathrm{~m}$ dari pangkal batang. Faktor yang mempengaruhi kualitas tabur adalah kondisi hanca dan pelepah. Tenaga penabur cenderung melakukan aplikasi tepat pada ujung tajuk mengarah ke luar sehingga banyak pupuk yang melebihi batas standar. Pengaruh bahan pupuk yang berat membuat tenaga tabur kesulitan melakukan penaburan sehingga hasilnya tidak tepat cara sesuai dengan yang direkomendasikan.

Cara aplikasi TKKS disesuaikan dengan umur tanaman karena dilihat dari perkembangan akar. Fase TBM pada aplikasi TKKS dilakukan secara melingkar satu lapis sedangkan pada TM aplikasi diletakan pada jarak antar tanaman satu lapis dan menutupi permukaan tanah. Cara aplikasi yang tepat pada TKKS dapat meningkatkan efektifitas pemupukan namun apabila salah aplikasi dapat menimbulkan masalah yaitu serangan hama Oryctes rhinoceros, itulah sebabnya aplikasi dilakukan hanya satu lapis. Penentuan tepat cara dilakukan dengan mengukur tinggi TKKS yang telah terlebih dahulu dilakukan kalibrasi dengan tinggi tidak boleh melebihi 40 $\mathrm{cm}$. Data menunjukan bahwa persentase tepat cara aplikasi TKKS yaitu sebesar $100 \%$ per tanaman (Tabel 6). Terdapat faktor yang mempengaruhi ketepatan cara aplikasi TKKS di Sekunyir Estate. Pertama, aplikasi TKKS dosis yang digunakan relatif lebih sedikit yaitu $165 \mathrm{~kg}$ per titik sehingga mempermudahkan dalam aplikasi karena akan lebih cepat. Kedua, keadaan lahan yang datar membuat peletakan TKKS menjadi lebih mudah. Aplikasi TKKS di Sekunyir Estate sudah dilakukan tepat cara sehingga dapat mencegah meningkatnya serangan hama Oryctes rhinoceros.

\section{Efisiensi Pemupukan}

Efisiensi Biaya Pemupukan. Biaya pemupukan pada kelapa sawit berkisar antara 40$60 \%$ dari biaya pemeliharaan tanaman atau sekitar $30 \%$ dari total biaya produksi (Goh dan Hardter, 2003). Penggunaan biaya aplikasi pemupukan di Sekunyir Estate dapat dilihat pada Tabel 7, 8 dan 9.

Tabel 7. Biaya aplikasi pemupukan anorganik semester 2 tahun 2016

\begin{tabular}{lccrrc}
\hline Jenis pupuk & Luas (ha) & Tonase $(\mathrm{kg})$ & \multicolumn{1}{c}{ hk } & Total biaya $(\mathrm{Rp})$ & Biaya ha $^{-1}(\mathrm{Rp})$ \\
\hline HGFB & 881 & 11.970 & 100 & 123.032 .150 & 139.651 \\
CCM44 & 1.890 & 688.617 & 709 & 3.481 .862 .698 & 1.842 .255 \\
Kieserit & 289 & 13.958 & 52 & 43.533 .288 & 150.634 \\
\hline Total & 3.060 & 714.545 & 861 & 3.648 .428 .136 & 1.192 .297 \\
\hline
\end{tabular}


Tabel 8. Biaya aplikasi pemupukan organik semester 2 tahun 2016

\begin{tabular}{lcccccc}
\hline $\begin{array}{l}\text { Aplikasi } \\
\text { TKKS }\end{array}$ & TKKS (ton) & Luas (ha) & Dosis (ton ha ${ }^{-1}$ ) & Biaya (Rp) & $\begin{array}{l}\text { Biaya ha }^{-1} \\
\text { bulan }^{-1}(\text { Rp) }\end{array}$ & Status \\
\hline Februari & 108,22 & 2,6 & 40 & 2.114 .943 & 813.440 & TM \\
Maret & 457,64 & 16,2 & 30 & 8.943 .659 & 552.078 & TBM \\
April & 708,77 & 23,7 & 30 & 13.851 .492 & 584.451 & TBM \\
Mei & $1.018,76$ & 34,8 & 30 & 19.909 .627 & 572.116 & TBM \\
\hline Total & $2.355,15$ & 83,9 & 30 & 46.026 .696 & 548.590 & TBM \\
\hline
\end{tabular}

Tabel 9. Biaya yang dikeluarkan pada aplikasi pemupukan dalam 4 tahun terakhir

\begin{tabular}{lcccc}
\hline Aplikasi & \multicolumn{4}{c}{${\text { Biaya } \operatorname{tahun}^{-1}(\mathrm{Rp})}$} \\
\cline { 2 - 5 } pupuk & $2011 / 2012$ & $2012 / 2013$ & $2013 / 2014$ & $2014 / 2015$ \\
\hline Anorganik & 11.426 .336 .715 & 11.031 .878 .132 & 6.945 .171 .208 & 6.436 .344 .218 \\
TKKS & 483.731 .304 & 591.745 .804 & 320.536 .943 & 269.641 .507 \\
\hline
\end{tabular}

Analisa efisiensi biaya pemupukan anorganik pada semester 2 selama kegiatan magang dapat dilihat pada Tabel 7. Data menunjukan bahwa dari tiga jenis pupuk yang diaplikasikan pupuk CCM 44 memiliki biaya pengeluaran paling tinggi yaitu rata-rata sebesar Rp1 $842255.00 \mathrm{ha}^{-1}$ selama 4 bulan. Menurut Andayani (2008) penggunaan bahan pupuk tunggal lebih murah dibandingkan pupuk majemuk sehingga biaya bahan yang dikeluarkan pupuk majemuk akan lebih tinggi. Biaya aplikasi pada semua jenis pupuk anorganik di Sekunyir Estate adalah rata-rata sebesar Rp1 $192297.00 \mathrm{ha}^{-}$ 1 selama 4 bulan. Biaya pemupukan organik berupa TKKS semester 2 rata-rata sebesar Rp548 $590.00 \mathrm{ha}^{-1}$ bulan $^{-1}$ (Tabel 8). Pengeluaran biaya pemupukan organik di Sekunyir Estate terdiri dari biaya upah tenaga kerja dan biaya transportasi angkut TKKS ke lahan. Pengeluaran biaya terhadap penggunaan tenaga borongan di Sekunyir Estate dalam aplikasi TKKS lebih efisien jika dibandingkan dengan menggunakan tenaga SKU berdasarkan output yang didapat namun kualitas aplikasi lebih baik tenaga SKU jika dibandingkan dengan tenaga borongan.
Data biaya pemupukan anorganik tahun 2011-2013 terhadap biaya pemupukan tahun 2013-2015 terjadi penurunan sebesar 60\% (Tabel 9), hal ini dikarenakan faktor perubahan sistem organisasi pemupukan, perubahan penggunaan jenis pupuk dan keadaan tanaman. Biaya pemupukan organik juga terjadi penurunan sebesar 55\% (Tabel 9), hal ini disebabkan oleh kegiatan peremajaan sehingga jumlah TKKS berkurang.

Efisiensi Tenaga Kerja Pemupukan. Efisiensi tenaga kerja pemupukan dilihat berdasarkan prestasi kerja dari tenaga pupuk. Tenaga kerja merupakan faktor penting dalam pelaksanaan teknis aplikasi pupuk. Prestasi tenaga kerja yang baik dapat meningkatkan hasil pekerjaan yang akan berdampak pada ketepatan waktu aplikasi dan efisiensi biaya pemupukan. Tenaga kerja di Sekunyir Estate berjumlah sekitar 10-15 orang yang sebagian besar terdiri dari tenaga tetap SKU (Serikat Kerja Umum). Hasil rata-rata output aplikasi pupuk CCM 44 di Sekunyir Estate yaitu sebesar $961.14 \mathrm{~kg} \mathrm{hk}^{-1}$ (Tabel 10). Angka ini menunjukan bahwa tingginya output yang dihasilkan tenaga pupuk di Sekunyir Estate.

Tabel 10. Prestasi kerja tenaga pemupuk berdasarkan jenis pupuk

\begin{tabular}{llcc}
\hline Jenis pupuk & Standar & Output $\left(\mathrm{ha} \mathrm{hk}^{-1}\right)$ & Output $\left(\mathrm{kg} \mathrm{hk}^{-1}\right)$ \\
\hline HGFB & $7 \mathrm{ha} \mathrm{hk}^{-1}$ & 8.44 & 112.89 \\
CCM44 & $550 \mathrm{~kg} \mathrm{hk}^{-1}$ & 2.72 & 961.14 \\
Kieserit & $550 \mathrm{~kg} \mathrm{hk}^{-1}$ & 5.48 & 302.41 \\
Organik & Borongan & 0.20 & 5742.00 \\
\hline
\end{tabular}

Secara keseluruhan data menunjukan bahwa pupuk kieserit tidak melebihi standar karena dosis aplikasi kecil yaitu sekitar $300 \mathrm{~g}$ $\operatorname{tanaman}^{-1}$ yang artinya bahwa tenaga pupuk tidak akan menerima premi dari pemupukan kieserit. Dampak yang ditimbulkan di lapangan dari penentuan standar yang rendah adalah akan menurunnya kualitas pemupukan. Seharusnya kebijakan penentuan aplikasi pupuk dosis rendah harus sesuai dengan dengan standar seperti pupuk HGFB. Pemupukan HGFB dilakukan dengan dosis rendah yaitu $100 \mathrm{~g}$ tanaman $^{-1}$ dengan demikian standar premi ditentukan dari hasil luasan yang teraplikasi bukan tonase pupuknya. 
Hasil output aplikasi TKKS TBM di Sekunyir Estate adalah sebesar $0.2 \mathrm{ha} \mathrm{hk}^{-1}$ atau sebanyak 35 titik ha ${ }^{-1}$. Walaupun menggunakan sistem borongan namun perusahaan menargetkan output sebesar 0.28 ha hk $^{-1}$ atau sebanyak 49 titik hk ${ }^{-1}$. Penentuan standar ini bertujuan agar tidak terjadi restan TKKS di lapang karena akan mengakibatkan kandungan unsur hara kalium pada TKKS berkurang.

\section{Pengaruh Aplikasi TKKS terhadap Dosis Pemupukan Hara Kalium}

Kandungan unsur hara yang terdapat dalam TKKS sebagian besar mengandung unsur hara kalium. Tajuddin (2006) menyatakan bahwa TKKS memiliki kandungan kalium mencapai 1.46-2.41\% sehingga dengan penggunaan TKKS diharapkan dapat mampu mengurangi penggunaan pupuk kalium sehingga lebih efisien biaya. Analisis penggunaan dosis unsur hara kalium diambil dari hasil rekomdendasi LSU yang dikeluarkan oleh departemen riset MRC. Penggunaan dosis pupuk kalium pada lahan aplikasi TKKS terhadap lahan non aplikasi TKKS disajikan pada Tabel 11.

Tabel 11. Perbandingan dosis pupuk kalium pada lahan aplikasi TKKS terhadap lahan non aplikasi TKKS

\begin{tabular}{ccc}
\hline \multirow{2}{*}{ Tahun } & \multicolumn{3}{c}{${\text { Dosis aplikasi }\left(\mathrm{kg} \mathrm{tanaman}^{-1}\right)}^{-1}$} \\
\cline { 2 - 3 } & Aplikasi & Non aplikasi \\
\hline $2010-2011$ & $3.18^{\mathrm{a}}$ & $3.08^{\mathrm{a}}$ \\
$2011-2012$ & $3.00^{\mathrm{a}}$ & $3.08^{\mathrm{a}}$ \\
$2012-2013$ & $3.25^{\mathrm{a}}$ & $3.25^{\mathrm{a}}$ \\
$2013-2014$ & $2.75^{\mathrm{a}}$ & $2.75^{\mathrm{a}}$ \\
$2014-2015$ & $2.83^{\mathrm{a}}$ & $2.83^{\mathrm{a}}$ \\
\hline
\end{tabular}

Terdapat beberapa faktor yang menyebabkan pengurangan dosis pemupukan tidak dilakukan. Pertama, pada aplikasi TKKS di lapangan umumnya terjadi restan TKKS yang artinya banyak TKKS belum teraplikasi sehingga menumpuk di collection road dan menyebabkan kehilangan kandungan hara kalium akibat pencucian. Alasan ini disebabkan karena kurangnya tenaga kerja aplikasi TKKS yang sebagian besar adalah tenaga borongan. Kedua, aplikasi TKKS di Sekunyir Estate ditujukan untuk lahan dengan produktivitas kelapa sawit rendah sehingga setelah dilakukan LSU maka terjadi persamaan hara kalium antara lahan aplikasi TKKS terhadap lahan non aplikasi TKKS. Ketiga, aplikasi dosis yang dibutuhkan pertanaman belum sesuai dengan jumlah dosis yang dibutuhkan sehingga akan mempengaruhi hasil analisis rekomendasi penentuan dosis hara kalium.

\section{Pengaruh Aplikasi TKKS terhadap Produksi Kelapa Sawit}

TKKS adalah limbah dari hasil pengolahan TBS yang dapat dimanfaatkan sebagai pupuk untuk meningkatkan produktivitas kelapa sawit. PPKS (2011) menyatakan bahwa aplikasi TKKS memiliki pengaruh nyata terhadap peningkatan produktivitas sebesar $11.7 \%$. Pengaruh produktivitas kelapa sawit yang di aplikasikan TKKS terhadap non aplikasi pada tahun 2007-2015 secara statistik tidak berbeda nyata (Tabel 12). Banyak faktor yang mempengaruhi pengaruh TKKS terhadap produktivitas kelapa sawit. Pihak manajemen kebun mengungkapkan bahwa aplikasi TKKS bertujuan untuk meningkatkan produktivitas pada lahan yang marjinal atau kurang subur sehingga produktivitas kelapa sawit pada lahan marjinal dapat meningkat. Jika melihat data yang diperoleh bahwa hal ini berkorelasi positif terhadap pengaruh kebijakan manajemen kebun.

Tabel 12. Pengaruh aplikasi TKKS terhadap produktivitas TBS

\begin{tabular}{ccc}
\hline \multirow{2}{*}{ Tahun } & \multicolumn{2}{c}{${\text { Produktivitas }\left(\text { ton } \mathrm{ha}^{-1} \operatorname{tahun}^{-1)}\right.}$} \\
\cline { 2 - 3 } $2007-2008$ & Aplikasi & Non Aplikasi \\
$2008-2009$ & $28.55^{\mathrm{a}}$ & $29.51^{\mathrm{a}}$ \\
$2009-2010$ & $20.64^{\mathrm{a}}$ & $22.11^{\mathrm{a}}$ \\
$2010-2011$ & $19.13^{\mathrm{a}}$ & $19.07^{\mathrm{a}}$ \\
$2011-2012$ & $31.54^{\mathrm{a}}$ & $31.63^{\mathrm{a}}$ \\
$2012-2013$ & $24.50^{\mathrm{a}}$ & $24.78^{\mathrm{a}}$ \\
$2013-2014$ & $29.75^{\mathrm{a}}$ & $28.31^{\mathrm{a}}$ \\
$2014-2015$ & $28.47^{\mathrm{a}}$ & $29.97^{\mathrm{a}}$ \\
\hline
\end{tabular}


Program dan Realisasi Pemupukan Organik dan Anorganik

Manajemen pemupukan kelapa sawit suatu kegiatan yang bertujuan untuk memberikan kebutuhan hara tanaman untuk meningkatkan produktivitas. Perencanaan dalam kegiatan pemupukan meliputi penyusunan program kegiatan pemupukan. Program disusun berdasarkan jumlah tanaman kelapa sawit yang akan dipupuk, efektifitas aplikasi yang meliputi tepat waktu, jenis, cara dan dosis pemupukan hingga pada akhirnya akan dievaluasi apakah kegiatan pemupukan sudah sesuai dengan tujuan yang diharapkan. Program dan realisasi pemupukan organik dan anorganik di Sekunyir Estate disajikan pada Tabel 13 dan 14.

Tabel 13. Program dan realisasi pemupukan anorganik dalam 4 tahun terakhir

\begin{tabular}{ccccl}
\hline Tahun & Program $(\mathrm{kg})$ & Realisasi $(\mathrm{kg})$ & Pencapaian $(\%)$ & Status \\
\hline $2011 / 2012$ & 2877813 & 2819740 & 98 & TM \\
$2012 / 2013$ & 2959302 & 2934631 & 99 & TM \\
$2013 / 2014$ & 1353883 & 1036361 & 77 & TM + TBM \\
$2014 / 2015$ & 3216599 & 3163801 & 98 & TM + TBM \\
\hline Rata-rata & 2601899 & 2488633 & 93 & \\
\hline
\end{tabular}

Tabel 14. Program dan realisasi pemupukan TKKS dalam 4 tahun terakhir

\begin{tabular}{ccccl}
\hline Tahun & Program $(\mathrm{kg})$ & Realisasi $(\mathrm{kg})$ & Pencapaian $(\%)$ & Status \\
\hline $2011 / 2012$ & 22200 & 21106 & 95 & TM \\
$2012 / 2013$ & 26683 & 17598 & 66 & TM \\
$2013 / 2014$ & 0 & 23835 & 0 & TM + TBM \\
$2014 / 2015$ & 19444 & 25941 & 133 & TM + TBM \\
\hline Rata-rata & 17082 & 22120 & 74 & \\
\hline
\end{tabular}

Sekunyir Estate melakukan pencapaian prestasi aplikasi pupuk rata-rata sebesar 93\% tahun $^{-1}$ (Tabel 13). Angka ini menunjukan manajemen yang dilakukan di Sekunyir Estate sudah sangat baik namun pada tahun 2013/2014 terdapat pencapaian aplikasi sebesar $77 \%$ yang dikarenakan faktor perubahan kebijakan akibat replanting. Tujuan aplikasi pemupukan seharusnya adalah tepat realisasi $100 \%$ tahun $^{-1}$ karena untuk mencapai produksi yang optimum dibutuhkan aplikasi pemupukan secara keseluruhan. Pencapaian realisasi program aplikasi TKKS rata-rata sebesar $74 \%$ tahun $^{-1}$ (Tabel 14). Terdapat faktor yang mempengaruhi keberhasilan realisasi pemupukan TKKS. Pertama, aplikasi TKKS tergantung dari hasil pengolahan TBS yang dihasilkan PKS. Kedua, Aplikasi TKKS juga dipengaruhi oleh pembagian TKKS dari PKS untuk kebutuhan dua kebun yaitu Sekunyir Estate dan Seruyan Estate. Ketiga, ketersediaan tenaga kerja di lapang sulit didapatkan karena tenaga aplikasi TKKS menggunakan tenaga borongan.

\section{KESIMPULAN}

Kegiatan penelitian yang dilakukan selama 4 bulan telah meningkatkan pengetahuan dan kemampuan mahasiswa tentang budidaya baik secara teknis maupun manajerial khusunya manajamen pengelolaan pemupukan organik dan anorganik pada tanaman kelapa sawit. Manajemen pemupukan yang dilakukan di Sekunyir Estate telah dilakukan dengan baik dengan menerapkan prinsip tepat 4T (waktu, dosis, jenis, cara). Ketepatan waktu pada saat aplikasi pupuk anorganik, ketepatan dosis pupuk organik dan ketepatan cara aplikasi pupuk anorganik masih butuh dilakukan perbaikan agar efektifitas pemupukan meningkat. Sekunyir Estate telah melakukan efisiensi biaya sebesar $60 \%$ pada pemupukan anorganik dan $55 \%$ pada pemupukan organik mulai tahun 2013-2015. Efisiensi tenaga kerja dilihat dari prestasi kerja yang telah memenuhi standar dari setiap jenis aplikasi pupuk kecuali pupuk HGFB dan pupuk organik. Perencanaan dan pelaksanaan aplikasi pemupukan anorganik sudah sangat baik dengan rata-rata pencapaian realisasi pupuk sebesar $93 \%$ tahun $^{-1}$ namun pada aplikasi pemupukan organik rata-rata pencapaian realisasi hanya sebesar $74 \%$ tahun $^{-1}$. Pengaruh aplikasi TKKS terhadap peningkatan produktivitas dan pengurangan dosis unsur hara kalium tidak berpengaruh nyata karena banyak faktor dalam teknis aplikasi di lapang.

\section{DAFTAR PUSTAKA}

Adiwiganda, R. 2007. Manajemen Tanah dan Pemupukan Kelapa Sawit. Dalam S. Mangoensoekarjo (Eds.). Manajemen Tanah dan Pemupukan Budidaya Tanaman Perkebunan. Yogyakarta (ID): Gajah Mada University Press. 
Andayani, D. 2008. Pengelolaan pemupukan kelapa sawit (Elaeis guineensis Jacq.) tanaman menghasilkan di PT Era Mitra Agro Lestari (BSP Group), Sarolangun, Jambi. [Skripsi]. Program Sarjana, Institut Pertanian Bogor. Bogor.

[BPS] Badan Pusat Statistik. 2014. Produksi dan produktivitas pada tanaman kelapa sawit. [internet]. [diunduh 2015 Des 14]. Tersedia pada http://bps.go.id.

Cheng, H.T. 2010. Key Sustainability Issues in the palm oil sector. [internet]. [diunduh 2015 Des 14]. Tersedia pada www.ifc.org

[Ditjenbun] Direktorat Jenderal Perkebunan (ID). 2012. Statistik perkebunan Indonesia 1995-2014 kelapa sawit. [Internet]. [diunduh 2016 Agust 20]. Tersedia pada: http://ditjenbun.deptan.go.id.

Goh, K.J., Hardter, R. 2003. General oil palm nutrition. p.191-228. In T. Fairhurst, dan R. Hardter (Eds). Oil Palm Management for Large and Sustainable Yields.

Oil world. 2008. Oil World Annual 2010. [internet]. [diunduh 2015 Des 14]. Tersedia pada http://www.worldoil.com
Pahan, I. 2010. Panduan Lengkap Kelapa Sawit Managemen Agribisnis Dari Hulu Hingga Hilir. Jakarta (ID): Penebar Swadaya.

Poeloengan, Z., Fadli, M.L., Winarma, S., Rahutomo, E.S., Sutarta. 2003. Permasalahan pemupukan pada perkebunan kelapa sawit. Dalam W. Darmosarkoro, E.S. Sutarta, Winarna, (Eds.). Lahan dan Pemupukan Kelapa Sawit. Medan (ID): Pusat Penelitian Kelapa Sawit.

[PPKS] Pusat Penelitian Kelapa Sawit. 2005. Pemupukan Kelapa Sawit. Pusat Penelitian Kelapa Sawit. Medan.

Rahutomo, S., Sutarta, E.S., Siregar, H.H., Darlan, N.H., Winarna. 2008. Kemajuan Budidaya Kelapa Sawit di Indonesia. L.S, Purba (Eds.). Jakarta (ID): PPKS. hlm 145-155.

Tajuddin, M.H 2006. Fertilizer management in oil palm to improve crop yields The Planter 82:25-30. 